\title{
Assessing bronchodilator response in preschool children using spirometry
}

\author{
Luciano E Busi, ${ }^{1,2}$ Sebastián Restuccia, ${ }^{2}$ Ricardo Tourres, ${ }^{2}$ Peter D Sly ${ }^{3}$
}

- Additional material is published online only. To view please visit the journal online (http://dx.doi.org/10.1136/ thoraxjnl-2015-207961).

${ }^{1}$ Pulmonology Committee of the Argentinean Pediatric Society, Trelew, Argentina

${ }^{2}$ Trelew Hospital, Trelew, Argentina

${ }^{3}$ Children's Health and Environment Program, Child Health Research Centre, The University of Queensland, Brisbane, Australia

\section{Correspondence to}

Professor Peter Sly, Centre for Children's Health Research, 62 Graham St South Brisbane Qld 4101, Australia;

p.sly@uq.edu.au

Received 18 October 2015 Revised 20 September 2016 Accepted 26 September 2016 Published Online First 14 October 2016

\section{ABSTRACT}

Background Measuring lung function, including bronchodilator response (BDR), is an integral part of asthma management in older children. While spirometry is possible in preschool-aged children, the question remains whether measuring BDR aids in asthma diagnosis in this age group.

Methods 431 healthy children and 289 children with asthma, aged 3-5 years, were recruited from kindergartens and the pulmonology clinic in Trelew, Argentina. Spirometry was performed at visit 1 and repeated after $15 \mathrm{~min}$, with children randomised to placebo or salbutamol $(400 \mu \mathrm{g})$. Spirometry was again performed within 8 weeks at visit 2. Within-session repeatability from visit 1 and between-session reproducibility were calculated using baseline spirometry. The within-session repeatability and receiver operating characteristic curve analyses were used to determine the optimal threshold values for BDR for spirometry outcome variables measured at the first visit, and sensitivity, specificity and diagnostic accuracy were determined. Results As a group, children with asthma had lower lung function (FVC $1.11 \pm 0.12 \mathrm{~L}$ vs $1.01 \pm 0.15 \mathrm{~L}$; $\mathrm{FEV}_{0.75} 1.01 \pm 0.10 \mathrm{~L}$ vs $0.91 \pm 0.15 \mathrm{~L}$ ) and a greater BDR ( $\mathrm{FEV}_{0.75}$ group difference $8.6(95 \% \mathrm{Cl}-5.0$ to 14.3$) \%$ ) than healthy children. BDR was best defined by change in $\mathrm{FEV}_{0.75}$; an increase of $11 \%$ showed the best balance between sensitivity $(51 \%)$, specificity ( $88 \%)$, positive predictive value $(47 \%)$ and negative predictive value $(89 \%)$ for discriminating healthy from preschool-aged children with asthma.

Conclusions A negative BDR in a child suspected of having asthma makes a diagnosis of asthma less likely.

\section{INTRODUCTION}

The reported prevalence of asthma in preschool children in Western countries varies with up to $40 \%$ reporting wheeze in this age group. ${ }^{12}$ In addition, while $80 \%$ of children with persistent asthma started wheezing in early life only approximately $30 \%$ of preschoolers with recurrent wheeze are likely to progress to persistent asthma. ${ }^{1}$ Diagnosis and treatment of asthma in preschool children can be difficult, ${ }^{2-5}$ and mild or intermittent asthma is frequently underdiagnosed in this age group. ${ }^{1-8}$ However, persistent asthma generally begins in early life and establishing a diagnosis is important to ensure treatment is initiated appropriately. Since symptoms alone may be insufficient for making a definitive diagnosis, especially in resource-limited settings, ${ }^{2}$ objective measures to detect airway obstruction may aid this process. ${ }^{2}$ In recent years,

\section{Key messages}

What is the key question?

- Is bronchodilator response using spirometry useful in determining which wheezy preschoolaged children have asthma?

\section{What is the bottom line?}

- A negative bronchodilator response in young children suspected of having asthma can be useful in excluding asthma.

\section{Why read on?}

- This manuscript provides data on the reproducibility and repeatability of spirometry, what constitutes a bronchodilator response using spirometry and the diagnostic performance of spirometry in children aged 3-5 years.

techniques for measuring lung function in preschoolers have become more generally available and standardised methodologies for several tests, including spirometry, have been reported. ${ }^{9}$ Reasonable success in measuring lung function in preschoolers has been reported (see online supplementary table E1) if they are properly motivated and supervised by appropriately experienced staff; however, success is lower in younger children and variable between studies. ${ }^{2-5}$

Measurement of bronchodilator response (BDR) using spirometry in children older than 6 years of age is well established and standardised, while the diagnostic accuracy is influenced by the prevalence of asthma in the study population. ${ }^{2} 3510$ However, just what constitutes a BDR for younger children is poorly defined. ${ }^{2} 39$ 11-14 $^{11}$ Many different methods for determining BDR have been reported (see online supplementary table E2); the most common being to define a positive BDR as being below the fifth percentile (or above the 95th percentile, depending on the direction of change) of (usually a small number of) the response of healthy control subjects to inhaled bronchodilator. The European Respiratory Society-American Thoracic Society (ERS-ATS) joint task force on preschool lung function testing ${ }^{9}$ recommended that assessment of BDR should be based on the within-subject-between-test repeatability for the desired outcome variable. Therefore, the objectives of the present study were to define a BDR, measured using spirometry, in 
terms of repeatability and reproducibility in healthy preschoolers and in those with diagnosed asthma. In addition, we wished to examine the diagnostic accuracy of BDR in determining which children with respiratory symptoms require further evaluation to determine whether they are likely to have asthma.

\section{METHODS}

\section{Study population}

Children aged 3-5 years were recruited from kindergartens selected randomly from the city of Trelew, Argentina (431 healthy children and 88 with asthma) and from the paediatric pulmonology clinic at the Trelew Hospital (201 with asthma). Children were excluded if they had any of the following: pathology that impeded the performance of spirometry, a respiratory disease other than asthma, experience in performing spirometry, respiratory symptoms in the previous 3 weeks, received corticosteroids or bronchodilators in the last 48 hours or if consent was not given by parents. Children were not excluded if their parents smoked, if they were born prematurely or if they were of low birth weight. Children with asthma had a positive diagnosis from the paediatric pulmonologist, using a locally produced standardised history and physical examination. Most children with asthma (83\%) were not taking any regular preventive medication. Healthy children gave negative responses to a recently validated asthma screening questionnaire with a 98.4\% negative predictive value ${ }^{15}$ (see online supplementary table E3) and were confirmed as not having asthma by the pulmonologist.

\section{Measurement of lung function}

Spirometry was performed following ATS guidelines for preschoolers ${ }^{9}$ by the same technician on all occasions. The children were then randomised to receive placebo (propellant) or salbutamol $400 \mu \mathrm{g}$ before repeating the spirometry $15 \mathrm{~min}$ later. Aerosols were administered via an aerosol-holding chamber during tidal breathing. The entire procedure was repeated at a second visit 4-8 weeks later, with the child receiving the same aerosol as on the first visit. Forced expiratory volumes and flows were reported, together with the response to bronchodilator for appropriate outcome variables. Lung function was reported as both raw values and Z-scores ${ }^{16}{ }^{17}$ where possible.

\section{Statistical analysis}

Demographic data were compared between groups using Student's t-tests and $\chi^{2}$ tests, as appropriate. Within-subject intrasession variability was analysed using Student's t-tests and limits of agreement were derived as mean within-subject difference \pm 1.96 times the SD of the difference. The coefficient of repeatability (intrasession, $\mathrm{C}_{\text {intra }}$ ) was calculated after placebo as 1.96 times the SD of the intrasubject difference between the two sets of measurements obtained during the first visit. The coefficient of reproducibility (intersession, $\mathrm{C}_{\text {inter }}$ ) was calculated as 1.96 times the intrasubject difference between the two series of measurements made over a period of 8 weeks. ${ }^{9}$ Normality of the data was confirmed prior to using parametric tests.

Lung function outcomes were compared between healthy children and those with asthma in terms of baseline spirometry recorded on the first visit, $C_{i n t r a}, C_{i n t e r}$, BDR and differences $\mathrm{C}_{\text {intra }}-\mathrm{C}_{\text {inter, }}$, using Student's t-tests and analysis of variance as appropriate. The threshold to determine positive test of BDR for each of the spirometric outcome variables was calculated in two ways: (1) as the mean difference +1.96 SD following placebo in healthy children and (2) using a receiver operating characteristic (ROC) curve analysis including sensitivity and 1-specificity for BDR and calculating the area under the curve and the point at which sensitivity + specificity is greatest. All analyses were performed using SPSS V.20.0.

\section{RESULTS}

\section{Characteristics of the population}

Two hundred and eighty-nine children with asthma and 431 healthy children, who fulfilled the eligibility criteria, were recruited. Of these, 244 (84.5\%) children with asthma and 364 $(84.5 \%)$ healthy children were able to perform acceptable baseline spirometry, and $233(80.6 \%)$ children with asthma and 320 $(74.2 \%)$ of the healthy children performed successful spirometry on both visits (figure 1). Success in obtaining technically acceptable spirometry increased with the age of the children, $67.6 \%$ success in children under the age of 4 years and $88.5 \%$ success in children 4 years or older (figure 1).

The characteristics of the study population are summarised in table 1. Apart from family history, we did not find significant differences in demographic and anthropometric data, exposure to environmental tobacco smoke or perinatal background between healthy children and children with asthma (table 1). There were no significant differences in perinatal history, demographic and anthropometric data, exposure to environmental tobacco smoke or spirometric values between children with asthma recruited from kindergartens and those recruited from hospital (data not shown).

\section{Comparison of baseline pulmonary function tests in first visit}

Children performed an average of five forced expiratory manoeuvres (range 3-15) to produce reliable spirometry. Group mean spirometry results for healthy children and children with asthma measured at visit 1 are shown in table 2. Children with asthma, as a group, had lower lung function, when expressed in raw values (table 2) or as Z-scores (table 3). Seventeen per cent of the children with asthma had been prescribed inhaled corticosteroids (ICS). The data for children with asthma excluding these $17 \%$ are shown in the online supplementary tables E4 and $\mathrm{E} 5$.

\section{Repeatability and reproducibility of spirometry}

The short-term, within-occasion repeatability of spirometry $\left(\mathrm{C}_{\text {intra }}\right)$, calculated from children randomised to repeat spirometry following placebo inhalation on visit 1 , is shown in table 4 and online supplementary table E6, excluding asthmatics prescribed ICS. There were no differences in $\mathrm{C}_{\text {intra }}$ or $\mathrm{C}_{\text {inter }}$ between healthy children and those with asthma for any spirometry variable (table 4 and online supplementary table E6). There were no significant differences between $\mathrm{C}_{\text {intra }}$ and $\mathrm{C}_{\text {inter }}$ for any spirometry variable in the healthy children. However, $C_{\text {inter }}$ was greater than $\mathrm{C}_{\text {intra }}$ for all variables in the children with asthma (table 4 and see online supplementary table E6), reaching statistical significance for $\mathrm{FEV}_{0.75}$ (24.2\% vs $12.1 \%$, $\mathrm{p}=0.034$ ).

\section{Bronchodilator response}

Changes in lung function following salbutamol inhalation measured at visit 1 are shown in table 2 and online supplementary table E4 (absolute values) and table 5 and online supplementary table E7 (per cent change). After salbutamol inhalation, children asthma showed significant increases in $\mathrm{FEV}_{0.75}$ (mean 13.2\% (SD 11.4), $\mathrm{p}<0.001$ ) and $\mathrm{FEV}_{1}$ (mean 10.3\% (SD 8.7), $\mathrm{p}<0.001)$. The increase in all spirometric variables was greater in children with asthma than in healthy children (table 5 and see online supplementary table E7). Using the change in 


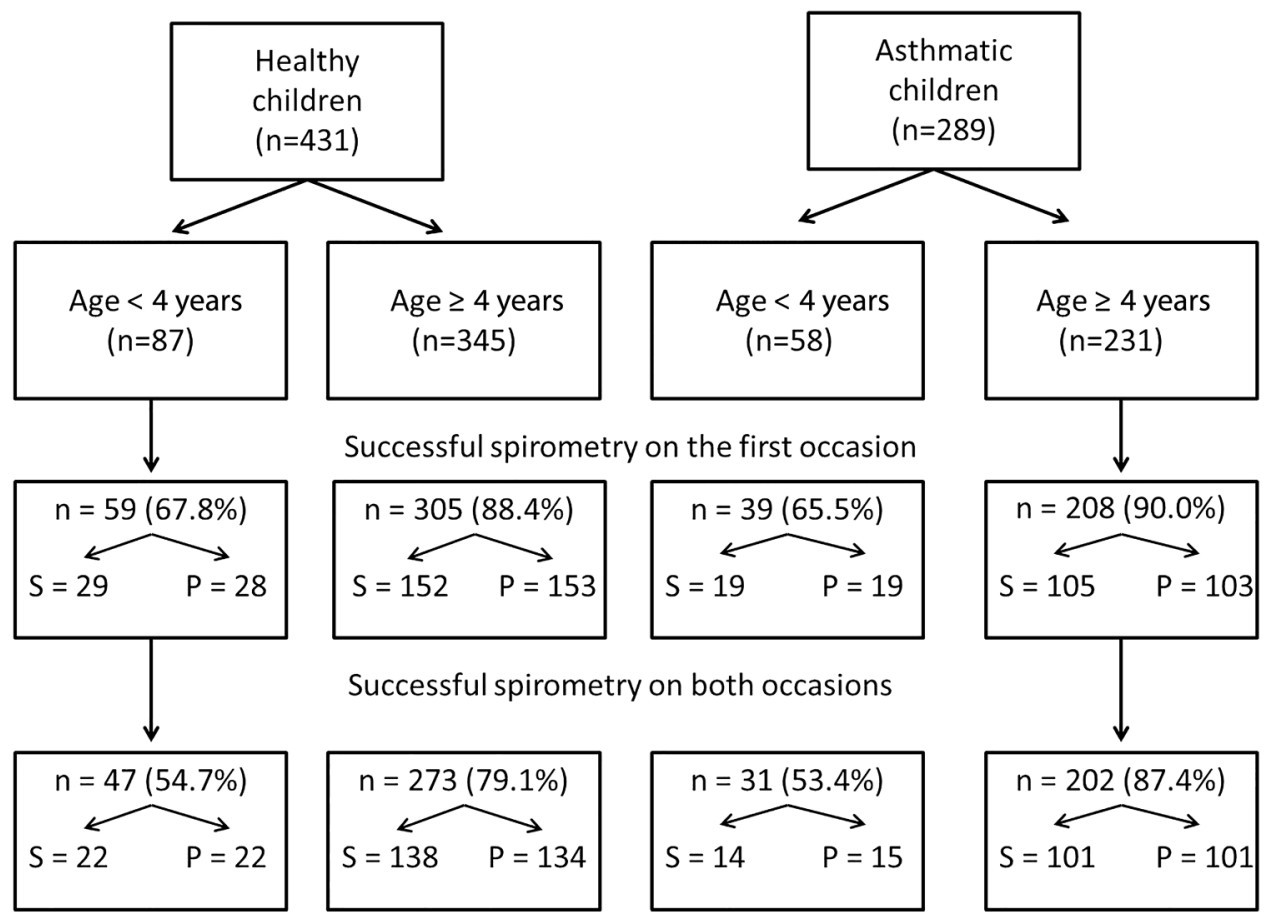

Figure 1 A consort diagram showing the flow of children through the study. $S$ indicates children who received salbutamol inhalation and $P$ indicates children who received placebo inhalation. Note: children were randomised to S or P on the first visit and received the same aerosol on the second occasion.

spirometric variables seen in the healthy group following placebo inhalation (see online supplementary table E8), the threshold for a positive BDR would be an increase of $14.4 \%$ in $\mathrm{FEV}_{0.75}, 16.9 \%$ in $\mathrm{FEV}_{1}$ and $48.2 \%$ in $\mathrm{FEF}_{25-75}$ (table 6 and see online supplementary table E9). An appropriate threshold suggested by ROC curve analyses for a positive BDR was $11 \%$ for $\mathrm{FEV}_{0.75}, 7 \%$ for $\mathrm{FEV}_{1}$ and $31 \%$ for $\mathrm{FEF}_{25-75}$. The threshold values for all spirometric variables are shown in table 6 and online supplementary table E9, together with the number of children classified as having a positive BDR using each method to determine a positive BDR. Understandably more children were classified as having a positive BDR using the threshold values obtained from ROC curve analyses.

The ability of a change in each spirometric variable to discriminate between healthy children and those with asthma calculated using ROC curve analyses is shown in table 7 and online supplementary table E10. The variable with the best discrimination was $\mathrm{FEV}_{0.75}$, with an area under ROC curve of 0.70. A fall in $\mathrm{FEV}_{0.75}$ of $11 \%$ was associated with a sensitivity of $51 \%$ and specificity of $88 \%$, with a positive predictive value of $47 \%$ and negative predictive value of $89 \%$. These values were essentially unchanged when $17 \%$ of children with asthma, who were prescribed ICS, were excluded from the analyses.

\section{DISCUSSION}

The data from the present study demonstrated that measuring BDR in preschool-aged children using spirometry can aid in determining which children have asthma. The most discriminatory variable was $\mathrm{FEV}_{0.75}$, with an increase of $11 \%$ defined as a positive BDR. A negative BDR could exclude a diagnosis of asthma, with a high degree of certainty in young children.

Traditionally, the most commonly used spirometric variable has been $\mathrm{FEV}_{1}$, especially in adults and older children. ${ }^{16}$ The utility of $\mathrm{FEV}_{1}$ comes from the fact that, provided a reasonable forced expiratory effort is made, expiratory flow limitation is likely to be induced and maintained to expiratory volumes exceeding $\mathrm{FEV}_{1}{ }^{9}{ }^{9}$ Under these circumstances, the flow-limited proportion of the expiratory flow-volume curve reflects the diameter and mechanical properties of the airways. Unfortunately these useful physiological conditions are unlikely to apply to the measurement of $\mathrm{FEV}_{1}$ in young children. ${ }^{9}{ }^{17-19}$ In a large cohort of children aged 5-7 years, Joseph-Bowen et al

Table 1 Characteristics of the study participants

\begin{tabular}{|c|c|c|c|c|}
\hline & Asthma $(n=289)$ & Controls $(n=431)$ & Difference (mean $(95 \% \mathrm{CI})$ ) & p Value \\
\hline Male & $59 \%$ & $51 \%$ & $8 \%(-4 \%$ to $52 \%)$ & 0.25 \\
\hline GA (weeks, mean (SD)) & $38.6(1.2)$ & $38.7(1.1)$ & $0.1(-0.7$ to 0.7$)$ & 0.28 \\
\hline Age (years, mean (SD)) & $4.9(0.9)$ & $4.8(0.8)$ & $0.1(-0.3$ to 0.6$)$ & 0.29 \\
\hline Family history of atopy & $75 \%$ & $38 \%$ & $37 \%(11 \%$ to $59 \%)$ & $<0.001$ \\
\hline Family history of asthma & $69 \%$ & $6 \%$ & $63 \%(58 \%$ to $87 \%)$ & $<0.001$ \\
\hline Family history of eczema & $8 \%$ & $1 \%$ & $7 \%(0 \%$ to $14 \%)$ & 0.017 \\
\hline ETS exposure & $57 \%$ & $42 \%$ & $15 \%(5 \%$ to $23 \%)$ & 0.051 \\
\hline
\end{tabular}

ETS, environmental tobacco smoke; GA, gestational age at birth. 
Table 2 Spirometric data before and after inhaled bronchodilator in healthy children and those with asthma measured on the first visit

\begin{tabular}{|c|c|c|c|c|c|c|}
\hline \multirow[b]{2}{*}{ Spirometry } & \multicolumn{2}{|c|}{ Healthy children $(n=364)^{*}$} & \multirow[b]{2}{*}{$p$ Value } & \multicolumn{2}{|c|}{ Children with asthma $(n=244)^{*}$} & \multirow[b]{2}{*}{$p$ Value } \\
\hline & Baseline $($ mean \pm SD) & Post-bronchodilator $($ mean $\pm S D)$ & & Baseline (mean $\pm S D)$ & Post-bronchodilator (mean \pm SD) & \\
\hline $\mathrm{FVC}(\mathrm{L})$ & $1.17 \pm 0.16$ & $1.21 \pm 0.06$ & 0.720 & $1.16 \pm 0.20$ & $1.24 \pm 0.11 \dagger$ & 0.041 \\
\hline $\mathrm{FEV}_{1}(\mathrm{~L})$ & $1.11 \pm 0.12$ & $1.16 \pm 0.07$ & 0.567 & $1.01 \pm 0.15$ & $1.11 \pm 0.09 \dagger$ & 0.032 \\
\hline $\mathrm{FEV}_{0.75}(\mathrm{~L})$ & $1.01 \pm 0.10$ & $1.06 \pm 0.05$ & 0.482 & $0.91 \pm 0.12$ & $1.03 \pm 0.10 \dagger$ & 0.022 \\
\hline $\mathrm{FEV}_{0.5}(\mathrm{~L})$ & $0.90 \pm 0.09$ & $0.94 \pm 0.05$ & 0.538 & $0.81 \pm 0.11$ & $0.92 \pm 0.10 \dagger$ & 0.028 \\
\hline $\mathrm{FEF}_{25-75}(\mathrm{~L} / \mathrm{s})$ & $1.50 \pm 0.31$ & $1.65 \pm 0.28$ & 0.568 & $1.16 \pm 0.38$ & $1.54 \pm 0.41 \dagger$ & 0.018 \\
\hline $\mathrm{FEF}_{25}(\mathrm{~L} / \mathrm{s})$ & $0.99 \pm 0.20$ & $1.09 \pm 0.19$ & 0.564 & $0.77 \pm 0.25$ & $1.03 \pm 0.31 \dagger$ & 0.024 \\
\hline $\mathrm{FEF}_{50}(\mathrm{~L} / \mathrm{s})$ & $1.93 \pm 0.26$ & $2.11 \pm 0.38$ & 0.535 & $1.4 \pm 0.48$ & $2.01 \pm 0.56 \dagger$ & 0.019 \\
\hline $\mathrm{FEF}_{75}(\mathrm{~L} / \mathrm{s})$ & $1.26 \pm 0.14$ & $1.38 \pm 0.25$ & 0.508 & $0.99 \pm 0.32$ & $1.34 \pm 0.37 \dagger$ & 0.025 \\
\hline PEF (L/s) & $2.47 \pm 0.27$ & $2.69 \pm 0.44$ & 0.501 & $2.22 \pm 0.59$ & $2.64 \pm 0.84 \dagger$ & 0.042 \\
\hline
\end{tabular}

Data, as absolute values, are shown as group mean and SD.

${ }^{*}$ Number of children with successful spirometry on the first visit.

tStatistically significant increase following bronchodilator $(p<0.05)$.

FEF, forced expiratory flow; PEF, peak expiratory flow.

Table 3 Baseline spirometry, reported as group mean Z-scores (mean), in healthy children and those with asthma measured on the first visit

\begin{tabular}{|c|c|c|c|c|}
\hline & $\begin{array}{l}\text { Children } \\
\text { with asthma } \\
\text { ( } n=244)\end{array}$ & $\begin{array}{l}\text { Healthy } \\
\text { children } \\
(n=364)\end{array}$ & $\begin{array}{l}\text { Difference } \\
\text { (mean }(95 \% \mathrm{CI}) \text { ) }\end{array}$ & $p$ Value \\
\hline z-FVC & -0.01 & 0.09 & $-0.10(-0.6$ to 0.08$)$ & 0.11 \\
\hline Z-FEV 1 & -0.44 & 0.25 & $-0.69(-0.98$ to 0.27$)$ & 0.008 \\
\hline$z-\mathrm{FEV}_{0.75}$ & -0.74 & 0.09 & $-0.83(-1.37$ to 0.27$)$ & 0.007 \\
\hline$z-\mathrm{FEV}_{0.5}$ & -0.55 & 0.06 & $-0.61(-1.41$ to 0.34$)$ & 0.007 \\
\hline$z-\mathrm{FEF}_{25-75}$ & -0.97 & -0.04 & $-0.93(-0.99$ to 0.23$)$ & $<0.001$ \\
\hline $\mathrm{z}-\mathrm{FEF}_{25}$ & -0.99 & -0.05 & $-0.94(-0.95$ to 0.13$)$ & 0.004 \\
\hline$z-\mathrm{FEF}_{50}$ & -0.89 & -0.01 & $-0.88(-0.92$ to 0.28$)$ & $<0.001$ \\
\hline $\mathrm{z}-\mathrm{FEF}_{75}$ & -0.83 & -0.01 & $-0.82(-0.89$ to 0.18$)$ & 0.005 \\
\hline$z-P E F$ & -0.25 & 0.02 & $-0.23(-0.30$ to 0.01$)$ & 0.12 \\
\hline
\end{tabular}

The difference between groups (mean and $95 \% \mathrm{Cls}$ ) are also shown. Significance between groups was assessed using Student's t-tests.

Baseline spirometry on visit 1.

FEF, forced expiratory flow; PEF, peak expiratory flow.

reported an $\mathrm{FEV}_{1}: \mathrm{FVC}$ ratio of approximately $94 \%$ in healthy children, very similar to that found in the present study (95\%) (table 2). The lung is essentially empty in young children after $1 \mathrm{~s}$ of forced expiration; thus $\mathrm{FEV}_{1}$ occurs at a very low lung volume and expiratory flow limitation is almost certainly not maintained at that volume. Similarly, in a Scottish study (see online supplementary table E1), 20\% of 5-year-old children reported to have 'acceptable' spirometry have a forced expiratory item of $<1 \mathrm{~s} .{ }^{19} \mathrm{On}$ theoretical grounds, it has been argued that $\mathrm{FEV}_{0.75}$ in a young child may represent similar physiology to that represented by $\mathrm{FEV}_{1}$ in older children and adults. ${ }^{17} 20$ The data from the present study would support that contention.

The diagnosis of asthma in young children essentially remains a clinical diagnosis with treatment frequently started on an empirical basis. Recent data have suggested that both underdiagnosis and over-diagnosis of asthma in young children remain a problem in many parts of the world, leaving a substantial global burden of disease due to asthma. ${ }^{21}$ Inappropriate treatment of young children with inhaled steroids and combination therapy is all too common. ${ }^{22}$ In an attempt to improve treatment targeted at young children, the ERS-ATS joint task force attempted to categorise young asthmatics into groups determined by their trigger
Table 4 Repeatability $\left(\mathrm{C}_{\text {intra }}\right)$ and reproducibility $\left(\mathrm{C}_{\text {inter }}\right)$ of spirometry, calculated using absolute values, in healthy children and those with asthma from lung function measured on the first visit before and after receiving placebo

\begin{tabular}{|c|c|c|c|c|c|c|}
\hline \multirow[b]{2}{*}{ Spirometry } & \multicolumn{2}{|c|}{$\begin{array}{l}\text { Healthy children } \\
(n=181)\end{array}$} & \multirow[b]{2}{*}{$\begin{array}{l}p \\
\text { Value }\end{array}$} & \multicolumn{2}{|c|}{$\begin{array}{l}\text { Children with } \\
\text { asthma }(n=124)\end{array}$} & \multirow[b]{2}{*}{$\begin{array}{l}p \\
\text { Value }\end{array}$} \\
\hline & $\begin{array}{l}C_{\text {intra }} \\
(\%)\end{array}$ & $\begin{array}{l}\text { C inter } \\
(\%)\end{array}$ & & $\begin{array}{l}C_{\text {intra }} \\
(\%)\end{array}$ & $\begin{array}{l}\text { C inter } \\
(\%)\end{array}$ & \\
\hline FVC & 12.0 & 12.3 & 0.699 & 12.9 & 18.2 & 0.117 \\
\hline $\mathrm{FEV}_{1}$ & 11.6 & 11.9 & 0.711 & 11.8 & 19.3 & 0.220 \\
\hline $\mathrm{FEV}_{0.75}$ & 11.8 & 11.9 & 0.891 & 12.1 & 23.0 & 0.108 \\
\hline $\mathrm{FEV}_{0.5}$ & 12.1 & 12.3 & 0.812 & 12.1 & 24.2 & 0.034 \\
\hline
\end{tabular}

Within-session repeatability $\left(\mathrm{C}_{\text {intra }}\right)$ calculated from children randomised to receive placebo inhalation on visit 1 ; between-session reproducibility $\left(C_{\text {inter }}\right)$ calculated from baseline spirometry performed at each visit.

Table 5 Change in lung function after salbutamol inhalation in healthy children and those with asthma measured on the first visit

\begin{tabular}{lcllr}
\hline & $\begin{array}{l}\text { Children with } \\
\text { asthma } \\
(\mathbf{n}=124)\end{array}$ & $\begin{array}{l}\text { Healthy } \\
\text { children } \\
(\mathbf{n}=181)\end{array}$ & $\begin{array}{l}\text { Difference } \\
\text { (mean }(95 \% \mathrm{CI}))\end{array}$ & p Value \\
\hline $\mathrm{FVC}(\%)$ & $7.2(9.7)$ & $3.2(5.2)$ & $4.0(0.2$ to 8.1$)$ & 0.032 \\
$\mathrm{FEV}_{1}(\%)$ & $10.3(8.7)$ & $4.3(6.3)$ & $6.0(-2.7$ to 10.8$)$ & 0.008 \\
$\mathrm{FEV}_{0.75}(\%)$ & $13.2(11.4)$ & $4.6(4.9)$ & $8.6(-5.0$ to 14.3$)$ & $<0.001$ \\
$\mathrm{FEV}_{0.5}(\%)$ & $14.1(12.6)$ & $5.1(6.0)$ & $9.0(-2.3$ to 11.4$)$ & 0.002 \\
\hline
\end{tabular}

Data are shown as group mean change (mean (SD)\%) within the asthmatic and healthy groups and the difference (mean $(95 \% \mathrm{Cls})$ ) between groups.

factors. ${ }^{7}$ Children who wheezed only with viral infections (viral wheeze) were considered unlikely to go on to persistent asthma and to be less likely to need or benefit from inhaled steroid. Conversely, children who wheezed with other viruses and other triggers (multi-trigger wheeze) were considered to be more likely to develop persistent asthma and more likely to benefit from preventive treatment. Unfortunately this classification is not stable in individual children and has not been shown to help in determining either asthma risk or treatment requirements. ${ }^{8}$ The data from the present study suggest that measuring BDR between episodes in those with intermittent viral-induced wheeze may indicate 
Table 6 Threshold values for positive bronchodilator response (BDR) defined from repeatability of spirometry in healthy children $\left(\mathrm{C}_{\text {intra }}\right)$ and from receiver operating characteristic (ROC) curve analyses

\begin{tabular}{|c|c|c|c|c|c|c|}
\hline & \multicolumn{3}{|l|}{$\mathrm{C}_{\text {intra }}$} & \multicolumn{3}{|l|}{ ROC } \\
\hline & \multirow[b]{2}{*}{ Threshold (\%) } & \multicolumn{2}{|l|}{ BDR, n (\%) } & \multirow[b]{2}{*}{ Threshold (\%) } & \multicolumn{2}{|l|}{ BDR, n (\%) } \\
\hline & & $\begin{array}{l}\text { Children with } \\
\text { asthma }(n=124)\end{array}$ & $\begin{array}{l}\text { Healthy children } \\
(n=181)\end{array}$ & & $\begin{array}{l}\text { Children with } \\
\text { asthma }(n=124)\end{array}$ & $\begin{array}{l}\text { Healthy children } \\
(n=181)\end{array}$ \\
\hline FVC & 13.3 & $29(23.4)$ & $9(5.0 \%)$ & 5 & $62(50.5)$ & $52(28.7 \%)$ \\
\hline $\mathrm{FEV}_{1}$ & 14.2 & $32(25.8)$ & $13(7.2 \%)$ & 7 & $61(49.2)$ & $34(18.8 \%)$ \\
\hline $\mathrm{FEV}_{0.75}$ & 13.5 & 49 (47.6) & $12(6.6 \%)$ & 11 & 64 (51.6) & $21(11.6 \%)$ \\
\hline $\mathrm{FEV}_{0.5}$ & 14.6 & $45(43.7)$ & $18(9.9 \%)$ & 12 & $65(52.4)$ & $39(21.5 \%)$ \\
\hline
\end{tabular}

The numbers of healthy children and children with asthma classified as having a positive BDR are also shown.

$\mathrm{BDR}$, bronchodilator response.

Table 7 Ability of change in a spirometric variable following salbutamol inhalation to discriminate between children with asthma and healthy children

\begin{tabular}{lllllll}
\hline Spirometry & Area & $\begin{array}{l}\text { Threshold } \\
(\%)\end{array}$ & $\begin{array}{l}\text { Sensitivity } \\
(\%)\end{array}$ & $\begin{array}{l}\text { Specificity } \\
(\%)\end{array}$ & $\begin{array}{l}\text { PPV } \\
(\%)\end{array}$ & $\begin{array}{l}\text { NPV } \\
(\%)\end{array}$ \\
\hline $\mathrm{FVC}$ & 0.51 & 5 & 50.0 & 71.3 & 54.4 & 67.5 \\
$\mathrm{FEV}_{1}$ & 0.66 & 7 & 49.1 & 81.0 & 34.4 & 88.7 \\
$\mathrm{FEV}_{0.75}$ & 0.70 & 11 & 51.2 & 88.4 & 47.1 & 89.0 \\
$\mathrm{FEV}_{0.5}$ & 0.66 & 12 & 52.3 & 78.2 & 32.7 & 89.0 \\
\hline
\end{tabular}

Area, area under the receiver operating characteristic curve; NPV, negative predictive value for excluding asthma; PPV, positive predictive value for detecting asthma; threshold, value of a spirometric variable giving the best balance between sensitivity and specificity.

which children are likely to have asthma; those with a negative BDR are unlikely to have asthma and may not warrant treatment. A systematic study to investigate this proposition would be worthwhile.

Precisely what constitutes a BDR in young children and how it should be defined remain controversial. We have previously argued that, as the magnitude of the change following bronchodilator is related to the degree of baseline obstruction, a relative change (ie, per cent change from baseline) should be reported. ${ }^{142324}$ There is no consistency in the literature for how a BDR should be defined in preschool-aged children (see online supplementary table E2). One report attempting to determine the clinical utility of $\mathrm{BDR}^{10}$ measured spirometry in 142 children, approximately $30 \%$ of who had a history of recurrent wheeze, and reported that an increase of $9 \%$ in $\mathrm{FEV}_{1}$ discriminated between the healthy and wheezy children with a sensitivity of $50 \%$ and specificity of $86 \%$; these results that are very similar to those reported in the present study for $\mathrm{FEV}_{1}$ (table 7), although with a higher threshold value $(9 \%$ vs $7 \%)$. FEV 0.75 was not included in that study. ${ }^{10}$ Most studies reporting BDR relate the threshold value to the short-term repeatability of the test or to the change following inhaled bronchodilator in healthy subjects (see online supplementary table E2); indeed this is recommended in official guidelines. ${ }^{9}$ However, as demonstrated in the present study, this may result in a higher threshold value and an underestimation of the number of children who have a positive BDR. Inclusion of a placebo in healthy children is not common but we argue that this is important to control for the non-specific effects of inhaling a substance on airway tone.

Importantly, the data from the present study showed that the within-occasion variability $\left(\mathrm{C}_{\text {intra }}\right)$ did not differ between healthy children and those with asthma. Having access to substantial populations of both healthy children and children with clinically verified asthma, as was the case in the present study, allows the use of ROC curve analyses to examine the discriminatory ability of a test for detecting asthma. Predictably, the negative predictive value is greater than the positive predictive value, indicating that a negative BDR in a child with a history suggestive of asthma is of more value in excluding asthma than is a positive BDR in 'diagnosing' asthma. We must point out, however, that the prevalence of asthma in our study population is lower $(17.0 \%, 88 / 519$ community-based children) than the $30 \%$ reported for preschoolers with recurrent wheeze who go on to develop persistent asthma. ${ }^{1}$ The population prevalence of asthma will influence the diagnostic accuracy (PPV, NPV) of any test for asthma and must be taken into consideration when applying data from one population to another.

We have previously attempted to improve the diagnosis of asthma in young children by developing and validating asthma screening questionnaires for use in school-aged children ${ }^{25}$ and preschool-aged children. ${ }^{15}$ In both age groups, these instruments proved to be more effective in determining which children were unlikely $(98.7 \%$ for school-aged children; $98.4 \%$ for preschoolers) to have asthma and who did not need further assessment or treatment. In the present study, we have taken this further with measuring BDR in preschoolers. Again, the lack of a positive BDR indicated, with $89 \%$ certainty, that the child did not have asthma. If excluding a diagnosis of asthma means that fewer children will be treated inappropriately with asthma preventive medication, this would be a worthwhile outcome. We did not assess the atopic status of the children in the present study and while atopy is an important risk factor for asthma, the place for atopy testing would be after the screening test has indicated the need for further evaluation.

\section{CONCLUSIONS}

We conclude that BDR assessed by spirometry is a reliable test to discriminate asthma in preschool children, with a greater ability to exclude asthma. We recommend $\mathrm{FEV}_{0.75}$ as the most useful spirometric variable for measuring BDR in this age group and an increase of $11 \%$ or more indicates a positive response. Further research is warranted to determine whether not treating children with a negative BDR, as we have defined, prevents the inappropriate use of asthma preventive medications.

Competing interests None declared.

Patient consent Obtained.

Ethics approval Trelew Hospital, Argentina.

Provenance and peer review Not commissioned; externally peer reviewed. 


\section{REFERENCES}

1 Castro-Rodriguez JA. The necessity of having asthma predictive scores in children. J Allergy Clin Immunol 2013;132:1311-13.

2 Lai CK, Beasley R, Crane J, et al. Global variation in the prevalence and severity of asthma symptoms: phase three of the International Study of Asthma and Allergies in Childhood (ISAAC). Thorax 2009;64:476-83.

3 Bush A. Practice imperfect--treatment for wheezing in preschoolers. N Engl J Med 2009:360:409-10.

4 Gappa M, Bush A. Pre-school wheeze: more questions than answers. Pediatr Pulmonol 2006:41:910-11.

5 Wildharber J, Hammer J. Asthma and wheezing disorders. In: Merkus PJ, Frey U, eds. Paediatric lung function. Sheffield, UK: European Respiratory Journals Ltd, 2010:209-24.

6 Bhatt JM, Smyth AR. The management of pre-school wheeze. Paediatr Respir Rev 2011;12:70-7.

7 Brand PL, Baraldi E, Bisgaard H, et al. Definition, assessment and treatment of wheezing disorders in preschool children: an evidence-based approach. Eur Respir J 2008;32:1096-110.

8 Schultz A, Devadason SG, Savenije OE, et al. The transient value of classifying preschool wheeze into episodic viral wheeze and multiple trigger wheeze. Acta Paediatr 2010;99:56-60.

9 Beydon N, Davis SD, Lombardi E, et al. An official American Thoracic Society/ European Respiratory Society statement: pulmonary function testing in preschool children. Am J Respir Crit Care Med 2007;175:1304-45.

10 Dundas I, Chan EY, Bridge PD, et al. Diagnostic accuracy of bronchodilator responsiveness in wheezy children. Thorax 2005;60:13-16.

11 Galant SP, Morphew T, Amaro S, et al. Value of the bronchodilator response in assessing controller naïve asthmatic children. J Pediatr 2007; 151:457-62. 62 e1.

12 Galant SP, Morphew T, Newcomb RL, et al. The relationship of the bronchodilator response phenotype to poor asthma control in children with normal spirometry. J Pediatr 2011:158:953-9.e1.
13 Pellegrino R, Antonelli A, Mondino M. Bronchodilator testing: an endless story. Eur Respir J 2010;35:952-4.

14 Thamrin C, Gangell CL, Kusel MM, et al. Expression of bronchodilator response using forced oscillation technique measurements: absolute versus relative. Eur Respir J 2010;36:212; author reply 3.

15 Busi LE, Sly PD, Llancaman L. Validation of a questionnaire for asthma case identification in preschoolers in Latin America. Respirology 2015:20:912-16.

16 Stanojevic S, Wade A, Cole TJ, et al. Spirometry centile charts for young Caucasian children: the Asthma UK Collaborative Initiative. Am J Respir Crit Care Med 2009;180:547-52.

17 Stanojevic S, Wade A, Stocks J. Reference values for lung function: past, present and future. Eur Respir J 2010;36:12-19.

18 Joseph-Bowen J, de Klerk NH, Firth MJ, et al. Lung function, bronchial responsiveness, and asthma in a community cohort of 6 -year-old children. Am J Respir Crit Care Med 2004;169:850-4.

19 Turner SW, Craig LC, Harbour PJ, et al. Spirometry in 5-year-olds--validation of curren guidelines and the relation with asthma. Pediatr Pulmonol 2007;42:1144-51.

20 Piccioni P, Borraccino A, Forneris MP, et al. Reference values of Forced Expiratory Volumes and pulmonary flows in 3-6 year children: a cross-sectional study. Respir Res 2007;8:14.

21 Murray C, Vos T, Lozano R, et al. Disability-adjusted life years (DALYs) for 291 diseases and injuries in 21 regions, 1990-2010: a systematic analysis for the Global Burden of Disease Study 2010. Lancet 2012;380:2197-223.

22 Van Asperen PP, Mellis CM, Sly PD, et al. Evidence-based asthma management in children--what's new? Med J Aust 2011;194:383-4.

23 Thamrin C, Gangell CL, Udomittipong K, et al. Assessment of bronchodilator responsiveness in preschool children using forced oscillations. Thorax 2007;62:814-19.

24 Beydon N. Assessment of bronchial responsiveness in preschool children. Paediatr Respir Rev 2006;7(Suppl 1):S23-5.

25 Busi LE, Sly PD, Restuccia S, et al. Validation of a school-based written questionnaire for asthma case identification in Argentina. Pediatr Pulmonol 2012:47:1-7. 